\title{
Evaluation of starch-clay composites as a pharmaceutical excipient in tramadol tablet formulations
}

\author{
Cecilia 0. Alabi ${ }^{1, B-D}$, Inderbir Singh ${ }^{2, A, C, D}$, Oluwatoyin Adepeju Odeku ${ }^{1, A, C-F}$ \\ ${ }^{1}$ Department of Pharmaceutics and Industrial Pharmacy, University of Ibadan, Nigeria \\ ${ }^{2}$ Chitkara College of Pharmacy, Chitkara University, Patiala, India \\ A - research concept and design; B - collection and/or assembly of data; $\mathrm{C}$ - data analysis and interpretation; \\ $D$ - writing the article; $E$ - critical revision of the article; $F$ - final approval of the article
}

Address for correspondence

Oluwatoyin Adepeju Odeku

E-mail: pejuodeku@yahoo.com

Funding sources

None declared

\section{Conflict of interest}

None declared

Received on September 3, 2020

Reviewed on 0ctober 12, 2020

Accepted on October 13, 2020
Cite as

Alabi CO, Singh I, Odeku OA. Evaluation of starch-clay composites as a pharmaceutical excipient in tramadol tablet formulations. Polim Med. 2020;50(1):33-40. doi:10.17219/pim/128473

DOI

10.17219/pim/128473

\section{Copyright}

○) 2020 by Wroclaw Medical University This is an article distributed under the terms of the Creative Commons Attribution 3.0 Unported (CC BY 3.0) (https://creativecommons.org/licenses/by/3.0/)

\author{
Abstract \\ Background. Co-processing starch with clay nanocomposite has been shown to yield a new class of ma- \\ terials, potentially with better properties than pristine starch, that could be used as directly compressible \\ excipients in tablet formulations.
}

Objectives. In this study, starches from 3 botanical sources, i.e., millet starch from Pennistum glaucum (L) $\mathrm{RBr}$ grains, sorghum starch from Sorghum bicolor L. Moench grains and cocoyam starch from Colocasia esculenta L. Schott tubers, were co-processed with montmorillonite clay (MMT) and evaluated as a directly compressible excipient in tramadol tablet formulations. The effects of different starch-to-clay ratios on the material and drug release properties of the resulting tablets were evaluated.

Material and methods. The starch-clay composites were prepared by heating a dispersion of the starch in distilled water, then precipitating the dispersion with an equal volume of $95 \%$ ethanol. The starch-clay composites were characterized and used as direct compression excipients for the preparation of tramadol tablets. The mechanical and drug release properties of the tablets were evaluated.

Results. Co-processing MMT with the starches yielded starch-clay composites with different material and tablet properties than the pristine starches. The co-processed starch-MMT biocomposites exhibited improved flowability and compressibility over the pristine starches. The mechanical and drug release properties of tramadol tablets containing starch-clay composites were significantly better than those containing only pristine starches. The properties of the starch-clay composites were not related to the botanical source of the starches.

Conclusions. The study showed that starch-clay biocomposites could be used in the controlled release of tramadol.

Key words: starch, tablets, excipients, biocomposite, dissolution test 


\section{Introduction}

In recent years, polymer-clay nanocomposites have received more attention due to their enhanced physicochemical and mechanical properties over the pure polymer systems. ${ }^{1-4}$ Biological nanocomposites have become a valuable addition to the existing nanocomposite materials that can be used to substitute petroleum-based composite materials in various applications due to their inherent biodegradability, availability and cost-effectiveness. ${ }^{4}$ Biopolymer-clay nanocomposites are prepared by adding low amounts of clay to the biopolymer matrix. ${ }^{5}$

Starch is one of the most abundant natural polymers that has become highly valuable due to its physical and chemical properties. However, native starch has poor compaction properties that have limited its application as a directly compressible excipient in tablet formulation. ${ }^{6,7}$ Co-processing starch with a clay nanocomposite has been shown to yield a new class of materials with the potential for more beneficial mechanical properties than the pristine material. ${ }^{8,9}$ The synergistic effect of starch and clay and the strong interfacial interactions (e.g., electrostatic and hydrogen bonding interaction) between the particles could improve the mechanical, swelling, water-uptake, thermal, drug-loading efficiency, and controlled-release behavior of the pristine biopolymer matrices. ${ }^{8}$ Montmorillonite (MMT) is one of the most commonly used natural clays that has been successfully applied in the preparation of nanocomposite systems. ${ }^{10-14}$ Montmorillonite is an aluminosilicate clay composed of tetrahedral layers of silica stacked between the octahedral layers of alumina. ${ }^{15}$ The isomorphic substitution of $\mathrm{Al}^{3+}$ for $\mathrm{Si}^{4+}$ in the tetrahedral layer and $\mathrm{Mg}^{2+}$ for $\mathrm{Al}^{3+}$ in the octahedral layer results in a net negative surface charge on the clay. Montmorillonite has a large specific surface area, and exhibits good adsorption, cation exchange and drug loading capacity. ${ }^{16}$ The individual crystals of MMT clay are not tightly bound, so water can infiltrate, causing the clay to swell and increase in volume when it absorbs water. ${ }^{4}$ Starch-MMT composite films have been shown to possess higher tensile strength and better water vapor barrier properties than films from pristine starch, due to the formation of an intercalated nanostructure. ${ }^{8}$

Recent studies have shown the potential of starches from different botanical sources to serve as excipients in tablet formulations. ${ }^{7,17,18}$ Native starches from millet (Pennistum glaucum (L) R Br, family Poaceae), sorghum (Sorghum bicolor L. Moench, family Gramineae) and cocoyam (Colocasia esculenta (L.) Schott, family Araceae) have been characterized and used as direct compression excipients in tramadol tablet formulations. ${ }^{19}$ One study revealed that the natural starches exhibited poor flowability and compressibility, which was not suitable for the preparation of tablets through direct compression. Therefore, in this study, millet, sorghum and cocoyam starches have been co-processed with MMT and evaluat- ed as a directly compressible excipient for the formulation of tramadol tablets for controlled drug delivery to provide consistent pain control with reduced dosage frequency and improved patient compliance. ${ }^{20}$ The effect of different starch-to-clay ratios on the material and drug release properties were also evaluated.

\section{Material and methods}

\section{Material}

The materials used were tramadol hydrochloride (Banson Pharmaceuticals, Patiala, India), MMT (SigmaAldrich, St. Louis, USA), dicalcium phosphate, polyvinylpyrrolidone ( $\mathrm{K}$ 30), talc, and magnesium stearate (all from Ipza Pharmaceuticals, Patiala, India). Grains of millet (Pennisetum glaucum) and sorghum (Sorghum bicolor), and tubers of cocoyam (Colocasia esculenta) were obtained from local farmers in Ibadan, Nigeria. The plant parts were authenticated and starches were extracted from the relevant plant parts using established procedures..$^{21}$ All other reagents used in the trials were of analytical grade.

\section{Methods}

\section{Preparation of starch-clay composites}

Starch-clay composites containing millet/sorghum/cocoyam starch and MMT in ratios of 1:0.5, 1:1, 1:2.5, and 1:5 were prepared by heating a dispersion of the starch in distilled water for $45 \mathrm{~min}$ on a hot plate and adding MMT. The dispersion was left on the hot plate $\left(100^{\circ} \mathrm{C}\right)$ with constant heating and stirring for $4 \mathrm{~h}$. The starch-clay mixture was allowed to cool to room temperature and was precipitated with an equal volume of $95 \%$ ethanol and stored at $4^{\circ} \mathrm{C}$ overnight. The precipitate was filtered and dried in a hot air oven at $100^{\circ} \mathrm{C}$ for $5 \mathrm{~h}$. The starch-clay composite was powdered using a laboratory mill and passed through a 60-mesh sieve, and then stored in an airtight container.

\section{Characterization of starch-clay composites}

\section{Scanning electron microscopy}

The surface morphology of the starch-clays composites was determined using a scanning electron microscope (SEM; Hitachi Model S 4300 SE/N SEM; Hitachi High Technologies, Singapore) at an accelerator potential of $10 \mathrm{kV}$. The samples were stuck on a specimen holder using a silver plate and then coated with palladium in a vacuum evaporator.

$\mathrm{pH}$ level

The $\mathrm{pH}$ of a $1 \% \mathrm{w} / \mathrm{v}$ water dispersion of the starch-clay composites was determined using a digital $\mathrm{pH}$ meter at $37 \pm 2^{\circ} \mathrm{C}$. 


\section{Loss on drying}

The starch-clay composites were weighed $\left(\mathrm{W}_{1}\right)$ and heated in an oven at $100 \pm 5^{\circ} \mathrm{C}$ until a constant weight was achieved. The samples were cooled in a desiccator and then reweighed $\left(\mathrm{W}_{2}\right)$. The percentage loss on drying (\% LOD) was calculated using the following formula:

$$
\mathrm{LOD}=\left[W_{1}-\frac{W_{2}}{W_{1}}\right] \times 100
$$

\section{Effective pore radius}

The effective pore radius was determined using the method of Goel et al. ${ }^{22}$ In brief, a micropipette tip (2 $\mathrm{mL}$, transparent) was filled with a starch-clay composite and weighed $\left(\mathrm{W}_{1}\right)$. N-hexane, whose surface tension $(\gamma)$ is $18.4 \mathrm{mN} / \mathrm{m}$, was poured dropwise on the bed top until the solvent filtered out at the bottom of the tip. The tip was reweighed $\left(\mathrm{W}_{\mathrm{f}}\right)$ and the effective pore radius was calculated using the following equation:

$$
\mathrm{R}_{\text {eff.P }}=\frac{\mathrm{W}_{\mathrm{f}}-\mathrm{W}_{\mathrm{i}}}{2 \pi \gamma}
$$

\section{Swelling index}

The initial bulk volume of the starch-clay composite in a 100-milliliter stoppered, graduated cylinder was determined. Water was then added in a sufficient quantity to produce a uniform dispersion. The sediment volume of the swollen mass was measured after $24 \mathrm{~h}$. The swelling index was calculated as:

$$
\text { SwellingIndex }=\left[\frac{V_{2}-V_{1}}{V_{1}}\right] \times 100
$$

where $\mathrm{V}_{1}$ and $\mathrm{V}_{2}$ are the volumes of the starch-clay composite before and after hydration, respectively.

\section{Bulk and tapped density}

The bulk density and tapped bulk density of the starchclay composite was determined in a 250-milliliter measuring cylinder using an automated volumeter (Vardhan Works Pvt. Ltd, Pune, India). Measurements were made in triplicate according to the European Pharmacopeia. ${ }^{23}$

\section{Flowability}

The Hausner ratio and Carr index were used to determine the flowability of the starch-clay composites. ${ }^{24}$ The flow rate of the starch-clay composites was determined using a steel funnel on a Pharmatest flow rate apparatus (Sartorius Pharmatest; Apparatebau GmbH, Hainburg, Germany) with an orifice of $15 \mathrm{~mm}$.

\section{Attenuated total reflectance-Fourier transform infrared spectroscopy}

The starch-clay composites were analyzed using an attenuated total reflectance-Fourier transform infrared spectroscopy (ATR-FTIR) spectrophotometer (Alpha; Bruker,
Yokohama, Japan). The samples were scanned in the spectral region from $4000 \mathrm{~cm}^{-1}$ to $400 \mathrm{~cm}^{-1}$ using the $\mathrm{KBr}$ pellet method.

\section{Formulation of tramadol hydrochloride tablets}

Tramadol hydrochloride tablets were formulated with the direct compression method according to the formulae provided in Table 1 . Batches (100 g) of each formulation were prepared by mixing the specified quantity of each ingredient in a tumble mixer for $15 \mathrm{~min}$. The blend was lubricated with talc and magnesium stearate, and the mixing was done for an additional $5 \mathrm{~min}$. The tramadol tablets were compressed using a multi-punch tableting machine (AK Industries, Nakodar, India) fitted with 6.75-millimeter biconcave round die punches.

Table 1. Composition of tramadol tablets

\begin{tabular}{|l|c|}
\multicolumn{1}{|c|}{ Ingredients } & Weight per tablet [mg] \\
\hline Tramadol & 100 \\
Starch-clay composite & 120 \\
Polyvinylpyrrolidone (K 30) & 25 \\
Talc & 2.5 \\
Magnesium stearate & 2.5 \\
Total & 250 \\
\hline
\end{tabular}

\section{Tablet properties}

\section{Crushing strength}

The crushing strength of the tablets was determined using a hardness tester (Perfit, Coimbatore, India). The force required to break a tablet was determined diametrically, and the averages for 6 tablets were calculated.

\section{Friability}

The friability of the tablets was measured using a friabilator (Model 902; EI Product, Panchkula, India). Twenty tablets were weighed and rotated at $25 \mathrm{rpm}$ for $4 \mathrm{~min}$. The tablets were reweighed after the removal of fines, and the percentage of weight loss was calculated.

\section{Disintegration time}

The disintegration time of the tablets was determined using a United States Pharmacopeia (USP) disintegration apparatus (EI Product) in $900 \mathrm{~mL}$ of $0.1 \mathrm{~N} \mathrm{HCl}\left(\mathrm{pH} 1.2,37^{\circ} \mathrm{C}\right)$.

\section{In vitro dissolution studies}

The in vitro dissolution time of the tramadol tablets was determined in $900 \mathrm{~mL}$ of $0.1 \mathrm{~N} \mathrm{HCl}(\mathrm{pH} 1.2)$ at $37 \pm 0.5^{\circ} \mathrm{C}$ using a USP XXIV dissolution apparatus II (DS 8000; Lab India, Pune, India) with a paddle stirring rate of 50 rpm. Aliquots $(5 \mathrm{~mL})$ were withdrawn at predetermined intervals and replaced with an equal volume of fresh medium. The samples were filtered through a 0.45 -micrometer membrane filter and analyzed for drug content using 
a double beam ultraviolet-visible (UV/VIS) spectrophotometer (Model 2202; Systronics, Ahmedabad, India) at $272 \mathrm{~nm}$. The drug concentration was calculated and expressed as a cumulative percent of the drug released.

\section{Statistical analysis}

Statistical analysis was carried out using analysis of variance (ANOVA) with GraphPad Prism ${ }^{\circledR}$ v. 4 computer software (GraphPad Software Inc. San Diego, USA). TukeyKramer multiple comparison tests were conducted to compare the effects of the excipients on the mechanical and drug release properties of the tablets. At a $95 \%$ confidence interval $(95 \% \mathrm{CI})$, p-values less than or equal to 0.05 were considered significant.

\section{Results and discussion}

\section{Characterization of starch-clay composites}

The SEM image of the starch-clay composite shown in Fig. 1 indicates irregularly shaped particles which differed from the granular-shaped ones reported for the native starches. ${ }^{19}$ Studies have reported that 2 types of hybrids are formed in starch-MMT composites: intercalated hybrids and exfoliated hybrids. ${ }^{25}$ In intercalated hybrids, the extended polymer chains are present between the clay layers, resulting in a multilayered structure with polymer/ inorganic layers at a repeated distance of a few nanometers. In exfoliated hybrids, the silicate layers are completely separated and dispersed in a continuous polymer
A

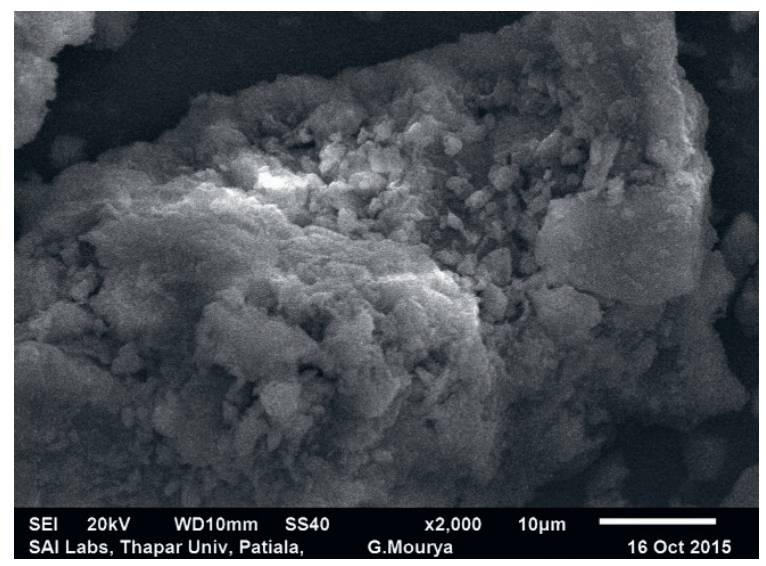

B

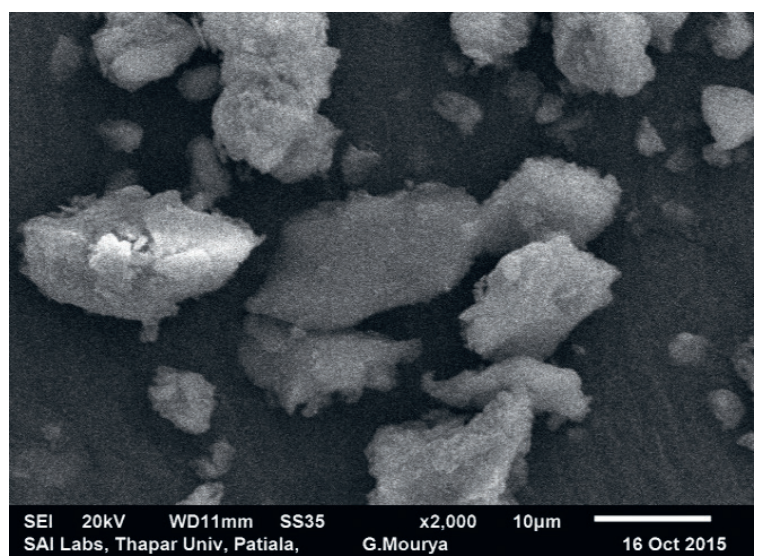

C

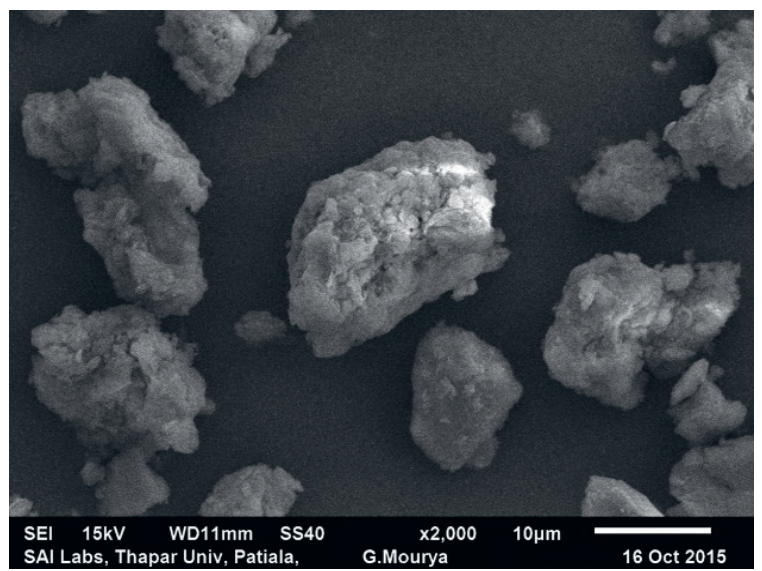

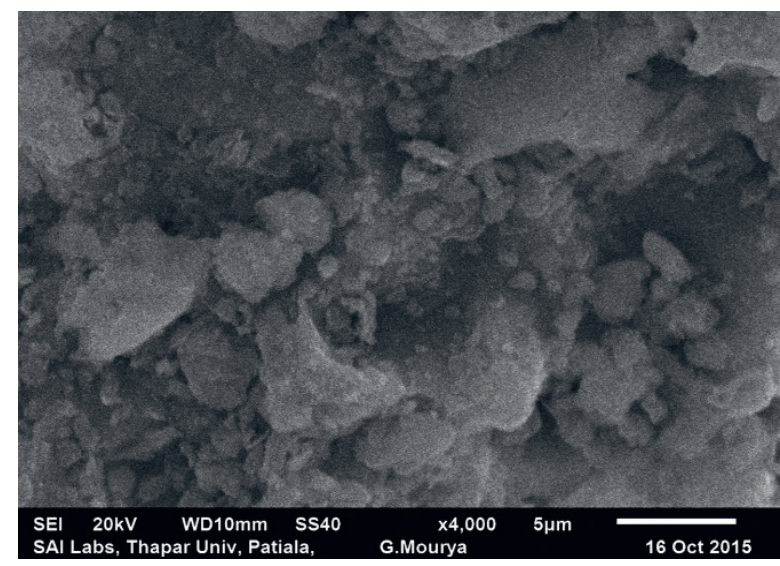
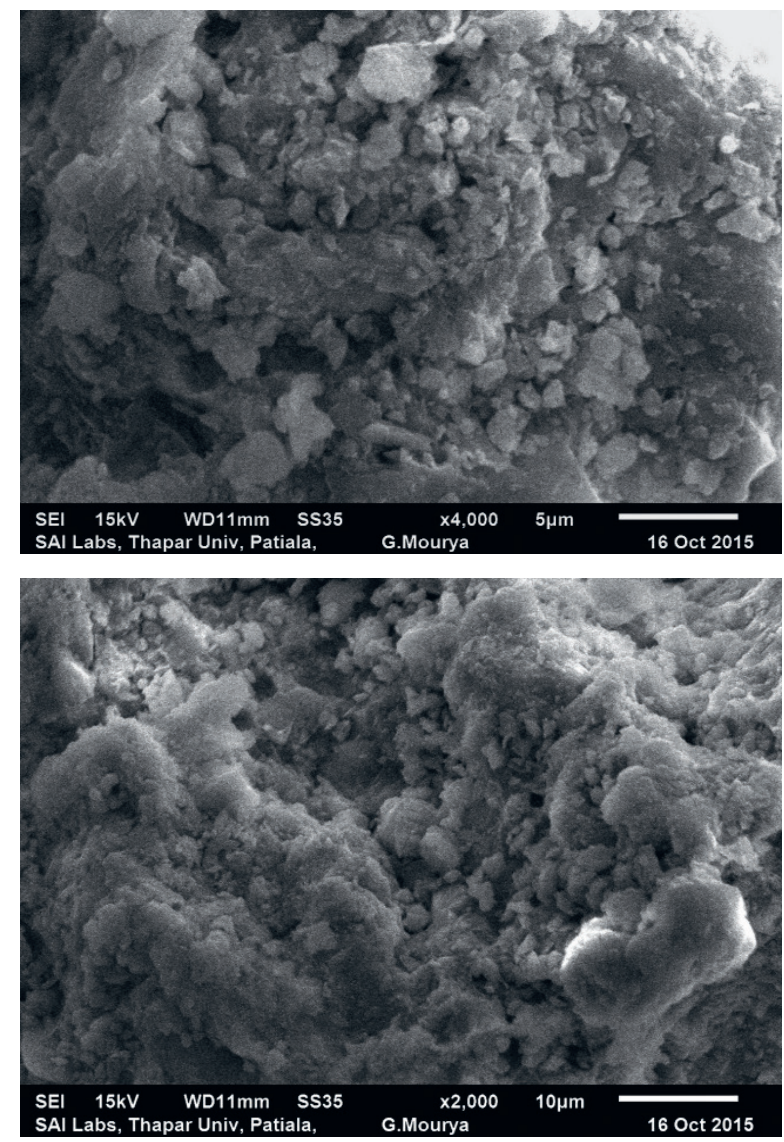

Fig. 1. SEM images of starch-montmorillonite clay composite (1:1) at different magnifications: (A) millet, (B) sorghum and (C) cocoyam 
Table 2. Material properties of the pristine starches and starch-clay composites

\begin{tabular}{|c|c|c|c|c|c|c|c|c|c|}
\hline $\begin{array}{l}\text { Parameter } \\
\text { material }\end{array}$ & $\begin{array}{l}\text { Starch-clay } \\
\text { composite }\end{array}$ & $\mathrm{pH}$ & $\begin{array}{c}\text { Loss } \\
\text { on drying } \\
{[\%]}\end{array}$ & $\begin{array}{c}\text { Effective } \\
\text { pore } \\
\text { radius }\end{array}$ & $\begin{array}{l}\text { Swelling } \\
\text { index } \\
{[\%]}\end{array}$ & $\begin{array}{c}\text { Bulk } \\
\text { density } \\
{\left[\mathrm{g} / \mathrm{cm}^{3}\right]}\end{array}$ & $\begin{array}{l}\text { Tapped density } \\
{\left[\mathrm{g} / \mathrm{cm}^{3}\right]}\end{array}$ & $\begin{array}{c}\text { Carr index } \\
{[\%]}\end{array}$ & $\begin{array}{l}\text { Hausner } \\
\text { ratio }\end{array}$ \\
\hline \multirow[t]{5}{*}{ Millet } & $1: 0$ & $6.0 \pm 0.0$ & $4.06 \pm 0.20$ & $1.62 \pm 0.22$ & $11.0 \pm 0.0$ & $0.215 \pm 0.002$ & $0.380 \pm 0.001$ & $43.42 \pm 0.02$ & 1.76 \\
\hline & 1:0.5 & $5.6 \pm 0.1$ & $4.07 \pm 0.01$ & $2.36 \pm 0.05$ & $56.2 \pm 0.2$ & $0.559 \pm 0.012$ & $0.718 \pm 0.005$ & $22.15 \pm 0.03$ & 1.28 \\
\hline & $1: 1$ & $5.2 \pm 0.2$ & $4.07 \pm 0.03$ & $2.42 \pm 0.07$ & $20.1 \pm 0.2$ & $0.559 \pm 0.000$ & $0.685 \pm 0.003$ & $18.42 \pm 0.01$ & 0.96 \\
\hline & $1: 2.5$ & $4.7 \pm 0.0$ & $4.07 \pm 0.03$ & $2.14 \pm 0.03$ & $9.1 \pm 0.0$ & $0.420 \pm 0.011$ & $0.580 \pm 0.002$ & $27.54 \pm 0.02$ & 0.85 \\
\hline & $1: 5$ & $4.4 \pm 0.1$ & $3.85 \pm 0.02$ & $2.18 \pm 0.02$ & $1.3 \pm 0.1$ & $0.419 \pm 0.002$ & $0.559 \pm 0.000$ & $25.03 \pm 0.00$ & 0.96 \\
\hline \multirow[t]{5}{*}{ Sorghum } & $1: 0$ & $6.0 \pm 0.1$ & $4.07 \pm 0.02$ & $2.09 \pm 0.02$ & $17.1 \pm 0.3$ & $0.268 \pm 0.001$ & $0.439 \pm 0.002$ & $38.95 \pm 0.00$ & 1.64 \\
\hline & $1: 0.5$ & $8.3 \pm 0.1$ & $8.02 \pm 0.22$ & $2.39 \pm 0.03$ & $367.3 \pm 0.2$ & $0.514 \pm 0.002$ & $0.665 \pm 0.011$ & $22.72 \pm 0.01$ & 1.29 \\
\hline & $1: 1$ & $7.4 \pm 0.0$ & $7.98 \pm 0.02$ & $2.31 \pm 0.04$ & $100.4 \pm 0.0$ & $0.471 \pm 0.009$ & $0.628 \pm 0.015$ & $24.99 \pm 0.02$ & 1.33 \\
\hline & $1: 2.5$ & $6.0 \pm 0.0$ & $7.96 \pm 0.14$ & $2.10 \pm 0.09$ & $17.2 \pm 0.2$ & $0.377 \pm 0.003$ & $0.595 \pm 0.003$ & $36.66 \pm 0.01$ & 1.58 \\
\hline & $1: 5$ & $5.4 \pm 0.1$ & $7.02 \pm 0.04$ & $2.09 \pm 0.22$ & $3.3 \pm 0.5$ & $0.353 \pm 0.002$ & $0.565 \pm 0.000$ & $37.47 \pm 0.02$ & 1.60 \\
\hline \multirow[t]{5}{*}{ Cocoyam } & $1: 0$ & $6.8 \pm 0.1$ & $4.07 \pm 0.03$ & $2.09 \pm 0.02$ & $17.2 \pm 0.2$ & $0.317 \pm 0.022$ & $0.513 \pm 0.004$ & $38.21 \pm 0.01$ & 1.62 \\
\hline & $1: 0.5$ & $7.4 \pm 0.0$ & $6.01 \pm 0.01$ & $2.35 \pm 0.01$ & $220.0 \pm 0.2$ & $0.580 \pm 0.001$ & $0.685 \pm 0.004$ & $15.40 \pm 0.02$ & 1.18 \\
\hline & $1: 1$ & $7.7 \pm 0.0$ & $6.00 \pm 0.02$ & $2.27 \pm 0.01$ & $56.1 \pm 0.1$ & $0.538 \pm 0.004$ & $0.628 \pm 0.003$ & $14.28 \pm 0.02$ & 1.17 \\
\hline & $1: 2.5$ & $7.8 \pm 0.0$ & $5.33 \pm 0.15$ & $2.15 \pm 0.06$ & $9.1 \pm 0.0$ & $0.397 \pm 0.021$ & $0.580 \pm 0.008$ & $31.58 \pm 0.03$ & 1.46 \\
\hline & $1: 5$ & $7.9 \pm 0.0$ & $5.70 \pm 0.03$ & $2.06 \pm 0.03$ & $4.3 \pm 0.2$ & $0.377 \pm 0.002$ & $0.538 \pm 0.002$ & $29.99 \pm 0.00$ & 1.43 \\
\hline
\end{tabular}

A

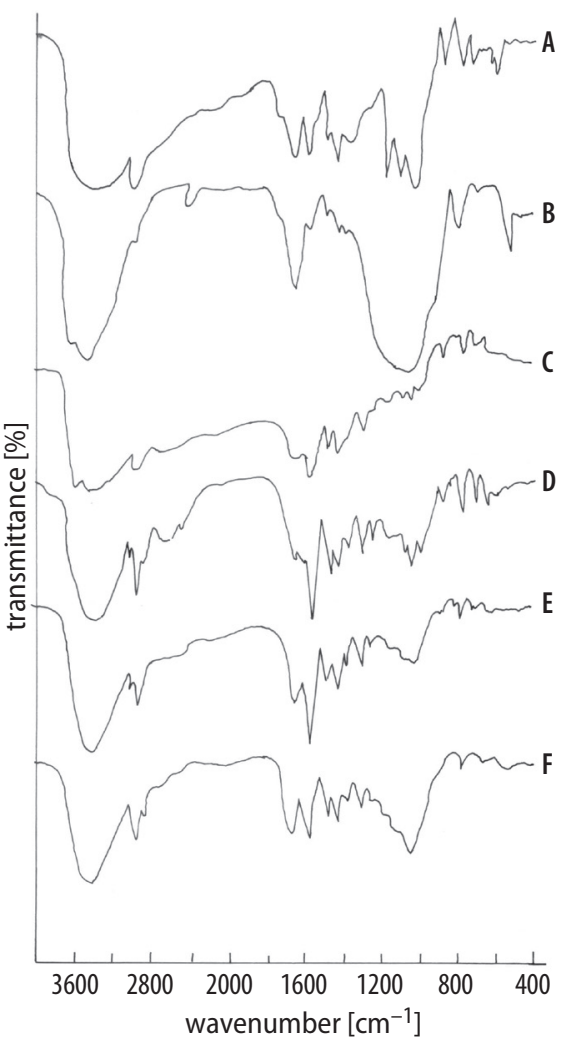

B

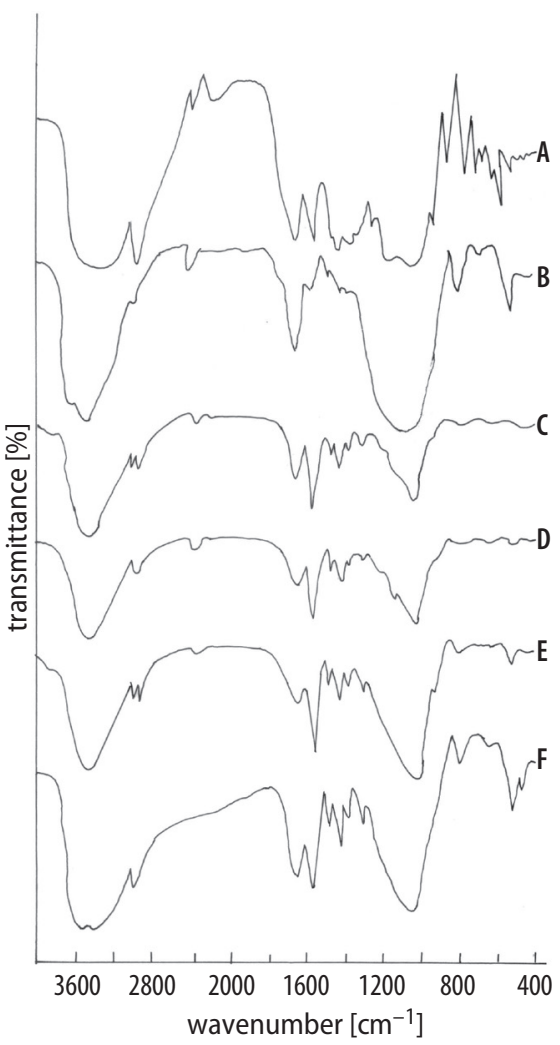

C

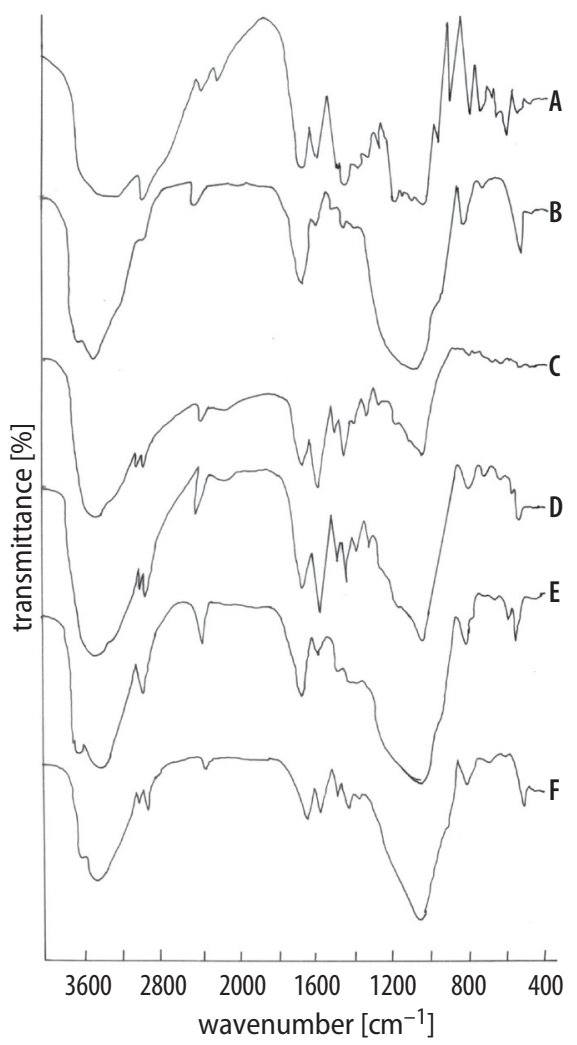

Fig. 2. FTIR spectra of (A) millet, (B) sorghum and (C) cocoyam pristine starch and starch-clay composites: native starch (A), montmorillonite clay (B), 1:0.5 starch-clay composite (C), 1:1 starch-clay composite (D), 1:2.5 starch-clay composite (E), and 1:5 starch-clay composite (F)

matrix. ${ }^{26}$ The SEM suggests that exfoliated hybrids were formed with the clay completely dispersed in the starch matrix for a hybrid with completely different properties from the pristine starch.
The results of the physicochemical and material properties of the starch-clay composites presented in Table 2 indicate that the biocomposites varied widely in their properties. The $\mathrm{pH}$ of the biocomposites ranged from 5.2 
to 8.3. The $\mathrm{pH}$ values generally decreased as the concentration of MMT in the biocomposite increased, except for the biocomposite containing cocoyam starch, where the $\mathrm{pH}$ increased. This indicates that the co-processing of millet and sorghum starches with MMT resulted in a more acidic biocomposite, while co-processing with cocoyam resulted in a more neutral $\mathrm{pH}$. The loss on drying is used to evaluate the moisture content of pharmaceutical powders; the percentage loss on drying decreased with the concentration of MMT in the biocomposite. The maximum moisture content prescribed for safe storage by most starch-producing countries is $13 \% \mathrm{w} / \mathrm{w}$, since higher levels of water can lead to microbial spoilage and subsequent deterioration in starch quality. ${ }^{27}$ The moisture content of all the biocomposites was within the specified limits for the proper storage of excipients. The pristine starches contain similar moisture content, while the biocomposites showed significantly higher ( $\mathrm{p}<0.05)$ moisture content than the pristine starches, except for the millet-MMT biocomposite, which did not demonstrate a significant increase in moisture content with an increase in MMT content.

The effective pore radius ranged from 1.62 to 2.42 , with the values decreasing as the concentration of MMT in the composite increased, although there were no significant $(\mathrm{p}>0.05)$ differences between the values. On the other hand, the swelling index of the starch-MMT composite at ratios of 1:0.5 and 1:1 were significantly $(\mathrm{p}<0.001)$ higher than those of the pristine starch, while at a starch-to-MMT ratio of $1: 2.5$ or $1: 5$, the values were statistically significant $(\mathrm{p}<0.05)$. There appears to be a limit to the concentration of MMT in the biocomposite mixture that would increase the swelling index of the composite. The degree of swelling also depended on the swelling index of the pristine starch, ranked as sorghum $>$ cocoyam $>$ millet. The starchclay composites exhibited more wicking action than the pristine starches. Swelling power is not only a measure of the hydration capacity of a material, but it is also indicative of the associative forces in the granules. ${ }^{28}$

The bulk and tapped densities of the starch-clay composites were higher than those of the pristine starch, but they decreased with an increase in the concentration of MMT in the biocomposites. The Carr index values and Hausner ratios generally decreased with an increase in the concentration MMT in the biocomposites. This indicates that the biocomposite exhibited better flowability and compressibility than the pristine starches. However, all the biocomposites showed Carr indices greater than 21 except the cocoyam-MMT biocomposite at ratios of 1:0.5 and 1:1. This indicates that co-processing starch with MMT improves the flowability and compressibility of starches, although the starch-clay composite cannot be said to be free-flowing.

The FTIR-ATR spectroscopy was used to analyze the interaction between the starches and MMT. Representative spectra for millet (Fig. 3) indicate that the pristine starch

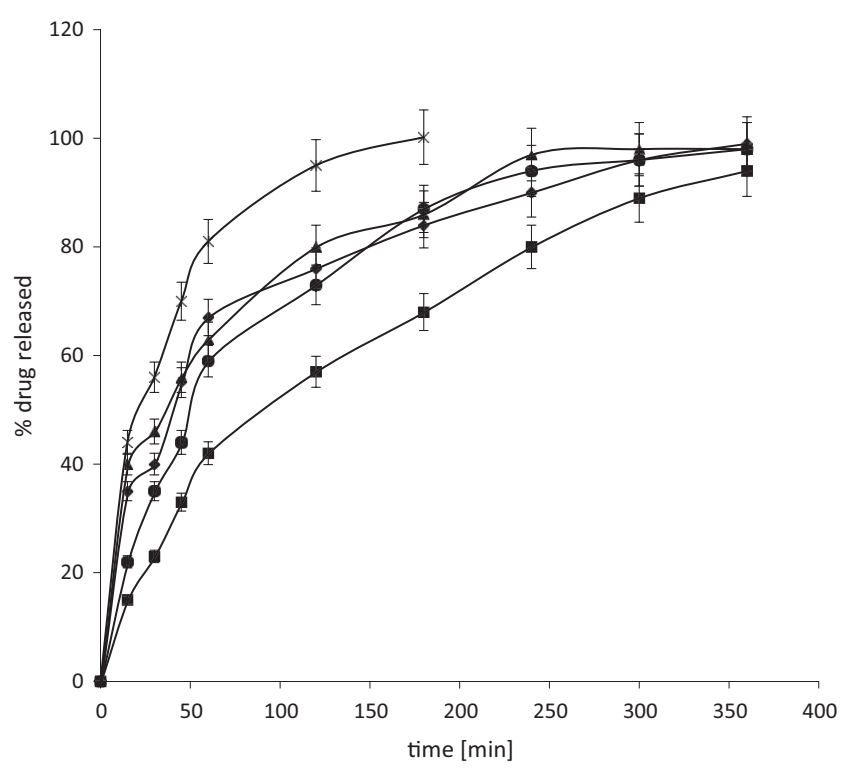

Fig. 3. Drug release profile of tramadol tablets containing native millet starch (*) and millet starch-clay composites at ratios of 1:0.5 (ש), $1: 1(\bullet), 1: 2.5(\bullet)$, and 1:5 (४)

exhibited a broad band at 3600-3200 $\mathrm{cm}$ due to OH groups in the starch molecules, $\mathrm{C}-\mathrm{H}$ stretching at $2925 \mathrm{~cm}^{-1}$, $\mathrm{C}=\mathrm{O}$ stretching at $1640 \mathrm{~cm}^{-1}, \mathrm{CH}_{2}$ symmetrical stretching vibration observed at $1370 \mathrm{~cm}^{-1}$, and $\mathrm{C}-\mathrm{C}, \mathrm{C}-\mathrm{O}, \mathrm{C}-\mathrm{O}-\mathrm{C}$, and $\mathrm{C}-\mathrm{O}-\mathrm{H}$ stretching from $1350 \mathrm{~cm}^{-1}$ to $850 \mathrm{~cm}^{-1}$. The peak at $897 \mathrm{~cm}^{-1}$ represents the saccharide group of the starch. On the other hand, the peak at $3619 \mathrm{~cm}^{-1}$ corresponds to the $\mathrm{OH}$ stretching vibration in MMT, the $\mathrm{H}-\mathrm{O}-\mathrm{H}$ bending of $\mathrm{H}_{2} \mathrm{O}$ is indicated by the peak at $1633 \mathrm{~cm}^{-1}$, and the peak at $1134 \mathrm{~cm}^{-1}$ indicates the $\mathrm{Si}-\mathrm{O}$ stretching vibrations, while the peak at $520 \mathrm{~cm}^{-1}$ indicates $\mathrm{Si}-\mathrm{O}$ bending. The peak at $919 \mathrm{~cm}^{-1}$ corresponds to $\mathrm{Al}-\mathrm{O}$ vibrations. ${ }^{9}$ The peaks around $3413 \mathrm{~cm}^{-1}, 1650 \mathrm{~cm}^{-1}$ and $1081 \mathrm{~cm}^{-1}$ show that the band of the starch overlapped with the bands of silicate, while at $1647 \mathrm{~cm}^{-1}$ the vibration band of silicate is unaffected. The soluble parts of the biopolymer containing $\mathrm{OH}$ and $\mathrm{NH}_{3}$ may form a hydrogen bond with MMT and the amide group of starch visible in the range of $1200-850 \mathrm{~cm}^{-1}$ is due to the MMT. The vibration band at $1599 \mathrm{~cm}^{-1}$ corresponds to the deformation vibration of the protonated amine group in the biocomposite; this group is shifted towards the lower frequency value of $1517 \mathrm{~cm}^{-1}$ in the biocomposite, which further indicates electrostatic interaction between such groups and the negatively charged sites in the clay structure. The intensity of these peaks varied largely due to the concentration of MMT in the composite.

\section{Tablet properties}

The crushing strength (CS) and friability (F) provide measures of tablet strength and weakness, respectively, ${ }^{29}$ and are a measure of the ability of tablets to withstand pressure or stress during handling, packaging, transpor- 
Table 3. Tablet properties of the pristine starches and starch-clay composites

\begin{tabular}{|c|c|c|c|c|c|c|c|c|}
\hline \multirow[b]{2}{*}{ Material } & \multicolumn{8}{|c|}{ Parameter } \\
\hline & $\begin{array}{l}\text { Starch-clay } \\
\text { composite }\end{array}$ & $\begin{array}{l}\text { Hardness } \\
{\left[\mathrm{kg} / \mathrm{cm}^{2}\right]}\end{array}$ & $\begin{array}{c}\text { Friability } \\
\text { [\%] }\end{array}$ & CSFR & $\begin{array}{l}\text { Disintegration } \\
\text { [min] }\end{array}$ & CSFR/DT & $t_{50}$ & $t_{80}$ \\
\hline \multirow[t]{5}{*}{ Millet } & $1: 0$ & $3.3 \pm 0.0$ & $0.48 \pm 0.02$ & 6.88 & $16.50 \pm 1.02$ & 0.42 & $20.0 \pm 2.0$ & $57.0 \pm 0.5$ \\
\hline & $1: 0.5$ & $3.5 \pm 0.0$ & $0.49 \pm 0.01$ & 7.14 & $29.70 \pm 2.00$ & 0.24 & $50.0 \pm 0.0$ & $240.0 \pm 3.0$ \\
\hline & $1: 1$ & $5.5 \pm 0.1$ & $0.26 \pm 0.04$ & 21.15 & $44.18 \pm 1.80$ & 0.48 & $90.5 \pm 2.5$ & $147.0 \pm 1.0$ \\
\hline & $1: 2.5$ & $5.0 \pm 0.1$ & $0.38 \pm 0.02$ & 13.16 & $25.53 \pm 1.92$ & 0.52 & $40.5 \pm 1.0$ & $146.0 \pm 0.0$ \\
\hline & $1: 5$ & $4.5 \pm 0.0$ & $0.37 \pm 0.01$ & 12.16 & $42.37 \pm 1.12$ & 0.29 & $36.6 \pm 2.0$ & $120.0 \pm 2.0$ \\
\hline \multirow[t]{5}{*}{ Sorghum } & $1: 0$ & $3.0 \pm 0.1$ & $0.03 \pm 0.00$ & 100.00 & $16.6 \pm 1.02$ & 6.02 & $16.0 \pm 1.0$ & $70.0 \pm 2.0$ \\
\hline & $1: 0.5$ & $4.5 \pm 0.1$ & $0.15 \pm 0.01$ & 30.00 & $27.03 \pm 1.15$ & 1.11 & $26.5 \pm 2.0$ & $76.5 \pm 3.0$ \\
\hline & $1: 1$ & $3.8 \pm 0.2$ & $0.27 \pm 0.01$ & 14.07 & $26.63 \pm 1.22$ & 0.53 & $46.5 \pm 2.0$ & $192.5 \pm 1.0$ \\
\hline & $1: 2.5$ & $4.3 \pm 0.0$ & $0.33 \pm 0.03$ & 13.03 & $30.48 \pm 1.12$ & 0.43 & $48.5 \pm 1.5$ & $260.0 \pm 2.0$ \\
\hline & $1: 5$ & $5.5 \pm 0.1$ & $0.54 \pm 0.01$ & 10.19 & $43.30 \pm 1.02$ & 0.24 & $40.5 \pm 2.0$ & $147.0 \pm 4.0$ \\
\hline \multirow[t]{5}{*}{ Cocoyam } & $1: 0$ & $3.3 \pm 0.1$ & $0.12 \pm 0.01$ & 27.50 & $19.0 \pm 2.01$ & 1.45 & $32.0 \pm 1.5$ & $110.0 \pm 2.0$ \\
\hline & $1: 0.5$ & $5.5 \pm 0.0$ & $0.26 \pm 0.02$ & 21.15 & $31.92 \pm 1.23$ & 0.66 & $52.3 \pm 1.0$ & $215.0 \pm 1.0$ \\
\hline & $1: 1$ & $7.0 \pm 0.1$ & $0.37 \pm 0.01$ & 18.92 & $26.02 \pm 0.92$ & 0.73 & $50.1 \pm 3.0$ & $135.0 \pm 2.5$ \\
\hline & $1: 2.5$ & $5.0 \pm 0.3$ & $0.38 \pm 0.02$ & 13.16 & $18.80 \pm 1.62$ & 0.70 & $39.5 \pm 2.0$ & $125.6 \pm 2.0$ \\
\hline & $1: 5$ & $5.5 \pm 0.0$ & $0.51 \pm 0.01$ & 10.78 & $16.65 \pm 1.96$ & 0.65 & $26.4 \pm 1.0$ & $170.0 \pm 1.0$ \\
\hline
\end{tabular}

CSFR - crushing strength-to-friability ratio; CSFR/DT - crushing strength-to-friability-to-disintegration ratio.

tation, and subsequent use. The results (Table 3) showed that tablets prepared with starch-clay composites generally exhibited higher crushing strength and friability than those prepared with pristine starches. The nature of the starch used for the starch-clay composite did not have a statistically significant effect $(p>0.05)$ on the mechanical properties of the tablets. All of the tramadol tablets exhibited friability values of less than $1 \% \mathrm{w} / \mathrm{w}$, which is within the pharmacopeia standards for compressed tablets. The CS-to-F ratio (CSFR) was used as a measure of the mechanical strength of the pharmaceutical tablets: the higher the CSFR, the stronger the tablet. ${ }^{29}$ The values of CSFR for the tramadol tablets indicates that the CSFR for tramadol tablets containing the pristine starches was generally higher than those of the starch-clay composites. This indicates that tablets made from the pristine starches exhibited more mechanical strength than those containing the starch-clay composites. The biocomposites containing sorghum starch exhibited the highest mechanical strength, while those containing millet starch exhibited the lowest values. Studies have shown that biocomposites can be considered a brittle or ductile material when the composite breaks with or without significant deformation under stress. ${ }^{3}$ Biocomposites that are brittle tend to break when subjected to stress without significant strain, but ductile composites deform before complete failure and tend to absorb energy before fracture. Thus, the biocomposites appeared more brittle than the pristine starches.

The disintegration time (DT) is regarded as the time required for the tablet to break into particles before dissolution occurs. The disintegration times for tramadol tablets containing the starch-clay composite are significantly $(\mathrm{p}<0.05)$ higher than those containing the pristine starches except for cocoyam starchclay composite at high-MMT ratios (ratios of 1:2.5 and 1:5), where the DT was lower. The strong interfacial interaction between the particles of the starch and clay yielded a starch-clay composite with a longer disintegration time. However, there is no clear-cut pattern regarding the effects of the clay concentration on the DT of the tablets. This suggests that the effect of the starchMMT biocomposite is probably due to several interacting factors. The crushing strength-to-friability-todisintegration ratio (CSFR/DT) was used to evaluate the balance between crushing strength and disintegration. A high CSFR/DT ratio indicates a better balance between the mechanical and disintegration properties of the tablets. ${ }^{29}$ The results show that tramadol tablets containing pristine starch exhibited a better balance than those containing the starch-clay composite, with the balance decreasing as the concentration of MMT in the biocomposite increased.

The amount of tramadol released was plotted over time; representative plots for the tramadol tablets containing millet starch-clay composites are shown in Fig. 3. The time for $50 \%$ and $80 \%$ drug release $\left(t_{50}\right.$ and $t_{80}$, respectively) derived from the plots are shown in Table 3. The results showed that the dissolutions times $t_{50}$ and $t_{80}$ generally decreased with an increase in MMT concentration. The DTs for tablets containing the biocomposites were significantly $(\mathrm{p}<0.01)$ higher than those containing the pristine starches. There appears to be no clear-cut pattern as to which starch will likely form a more rigid biocomposite that could yield a longer dissolution time. 


\section{Conclusions}

The results indicate that the co-processing of MMT with the 3 tropical starches yielded starch-clay composites that differed from the pristine starches in both their material and tablet properties. Co-processing starches with MMT improved the flowability and compressibility of the native starches. The mechanical and drug release properties of the tramadol tablets containing the starchclay composites were significantly better than those containing the pristine starches. There is no clear-cut pattern on the effects of the clay concentration or botanical properties of the starches. The starches from different botanical sources could be useful in the production of starch-clay composites for a variety of formulations depending on the mechanical and drug release profiles desired. The study showed that starch-clay biocomposites could be used in the controlled release of tramadol.

\section{ORCID iDs}

Cecilia O. Alabi (D) https://orcid.org/0000-0002-6336-611X Inderbir Singh (D) https://orcid.org/0000-0002-1860-4246 Oluwatoyin Adepeju Odeku (D) https://orcid.org/0000-0002-0732-1304

\section{References}

1. Bagdi K, Muller P, Pukanszky B. Thermoplastic starch/layered silicate composites: Structure, intercalation, properties. Comp Interf. 2006; 13(1):1-17.

2. Chiou BS, Yee E, Wood D, Shey J, Glenn G, Orts W. Effects of processing conditions on nanoclay dispersion in starch-clay nanocomposites. Cereal Chem. 2006;83(3):300-305.

3. Chung YL, Ansari S, Estevez L, Hayrapetyan S, Giannelis EP, Lai HM. Preparation and properties of biodegradable starch-clay nanocomposites. Carbohyd Polym. 2010;79:391-396.

4. Madhumitha G, Fowsiya J, Mohana RS, Thakur VK. Recent advances in starch-clay nanocomposites. Inter J Polym Analy Charac. 2018; 23(4):331-345.

5. Zhao R, Torley P, Halley PJ. Emerging biodegradable materials: Starch and protein-based bio-nanocomposites. J Mater Sci. 2008;43: 3058-3071.

6. Odeku OA, Picker-Freyer KM. Analysis of the material and tablet formation properties of four Dioscorea starches. Starch/Stärke. 2007; 59(9):430-444.

7. Odeku OA. Potentials of tropical starches as pharmaceutical excipients: A review. Starch/Stärke. 2013;65(1-2):89-106.

8. Tang X, Alavi S, Herald TJ. Barrier and mechanical properties of starch-clay nanocomposite films. Cereal Chem. 2008;85(3):433-439.

9. Thakur G, Singh A, Singh I. Formulation and evaluation of transdermal composite films of chitosan-montmorillonite for the delivery of curcumin. Int J Pharm Investig. 2016;6(1):23-31.
10. Giannelis EP. Polymer layered silicate nanocomposites. Advan Mat. 1996;8(1):29-35.

11. Paul DR, Robeson LM. Polymer nanotechnology: Nanocomposites. Polymer. 2008;49(15):3187-3204.

12. Pavlidou $S$, Papaspyrides $C D$. A review on polymer-layered silicate nanocomposites. Prog Polym Sci. 2008;33(12):1119-1198.

13. Raquez JM, Narayan R, Dubois P. Recent advances in reactive extrusion processing of biodegradable polymer-based compositions. Macromol Mat Eng. 2008;293:447-470.

14. Ray SS, Okamoto M. Polymer/layered silicate nanocomposites: A review from preparation to processing. Prog Poly Sci. 2003;28(11): 1539-1641.

15. Barton CD, Karathanasis AD. Clay minerals. In: Encyclopedia of Soil Science. New York, NY: Marcel Dekker Inc. US; 2007:187-190.

16. Yang H, Wang W, Zhang J, Wang A. Preparation, characterization, and drug-release behaviors of a $\mathrm{pH}$-sensitive composite hydrogel bead based on guar gum, attapulgite, and sodium alginate. Int J Polym Mater Polym Biomater. 2012;62(7):369-376.

17. Odeku OA, Awe OO, Popoola B, Odeniyi MA, Itiola OA. Compression and mechanical properties of tablet formulations containing corn, sweet potato, and cocoyam starches as binders. Pharm Tech. 2005;29(4):82.

18. Dare K, Akin-Ajani DO, Odeku OA, Odusote OM, Itiola OA. Effects of pigeon pea and plantain starches on the compressional, mechanical and disintegration properties of paracetamol tablets. Drug Dev Ind Pharm. 2006;32(3):357-365.

19. Alabi CO, Singh I, Odeku OA. Evaluation of natural and pregelatinized forms of three tropical starches as excipients in tramadol tablet formulation. J Pharm Investig. 2018;48(3):333-340.

20. Kizilbash A, Ngô-Minh C. Review of extended-release formulations of tramadol for the management of chronic non-cancer pain: Focus on marketed formulations. J Pain Res. 2014;7:149-161.

21. Young AH, In: Whistler RL, BeMiller JN, Pashall EF, eds. Starch Chemistry and Technology. London, UK: Academic Press; 1984:183-184,249-283.

22. Goel H, Kaur G, Tiwary A. K, Rana A. Formulation development of stronger and quick disintegrating tablets: A crucial effect of chitin. Yakugaku Zasshi. 2010;130(5):729-735.

23. European Pharmacopoeia: Directorate for the Quality of Medicines of the Council of Europe. $5^{\text {th }}$ ed. Strasbourg, France. 2007.

24. Carr RL. Evaluating flow properties of solids. Chem Eng. 1965;72: 163-168.

25. Müller CMO, Laurindo JB, Yamashita F. Composites of thermoplastic starch and nanoclays produced by extrusion and thermopressing. Carbohyd Polym. 2012;89(2):504-510.

26. Weiss J, Takhistov P, McClements J. Functional materials in food nanotechnology. J Food Sci. 2006;71(9):R107-R116.

27. Odeku OA, Schmid W, Picker-Freyer KM. Material and tablet properties of pregelatinized (thermally modified) Dioscorea starches. Eur J Pharm Biopharm. 2008;70(1):357-371.

28. Manek RV, Builders PF, Kolling WM, Emeje M, Kunle OO. Physicochemical and binder properties of starch obtained from Cyperus esculentus. AAPS PharmSciTech. 2012;13(2):379-388.

29. Odeku OA, Itiola OA. Evaluation of the effects of khaya gum on the mechanical and release properties of paracetamol tablets. Drug Dev Ind Pharm. 2003;29(3):311-320. 